\title{
Powder data
}

The crystals are so soft that trying to grind them into a powder tends to destroy their crystalline character. We therefore used a single crystal in the Gandolfi camera to obtain a powder pattern (Table 2). With a 10-hour exposure, at $36 \mathrm{kV}, 16 \mathrm{~mA}$, with $\mathrm{Ni}$-filtered $\mathrm{Cu} K$ radiation, only five powder lines could be measured.

The financial assistance of the National Research Council of Canada is gratefully acknowledged.

\section{References}

Donnay, J. D. H. \& Harker, D. (1937). Amer. Min., 22. 446-467.

Donnay, J. D. H. \& Donnay, G. (1961a). C. R. Acad. Sci. Paris, 252, 908-909, 1982-1983; 253, 291-292.

DonNay, J. D. H. \& DonNay, G. (1961b). Kristallografiva, 6, 840-846. [Engl. Trans.: Sor. Phys. Crystallogr. (1962). 6, 679-684.]

\section{Laboratory Note}

\section{J. Appl. Cryst. (1975). 8, 496}

\section{A very inexpensive device for collecting $X$-ray data below the ambient temperature}

In order to study a hydrated crystal which will decompose above $13^{\circ} \mathrm{C}$, kept in a Lindemann tube, a system has been conceived made up of three parts:

(A) a freezer of 50 litres capacity, 300 watts;

(B) a rectangular box with large dimensions;

(C) a large tube joining the freezer and the box to be cooled.

The box $B$ is made of aluminum or of galvanized sheet metal and is insulated from the inside by polystyrene foam. The box is sufficiently large to enclose the $X$-ray diffraction camera (single crystal, Weissenberg or precession).

The top of the box is closed with a lid. The lateral face $E$ of the box is replaced by a PVC plastic sheet capable of transmitting $X$-rays. The sheet is perfectly glued to the box borders and is in a loose condition so as to permit the adjustment of the camera close to the $X$-ray tube in the usual manner. In the

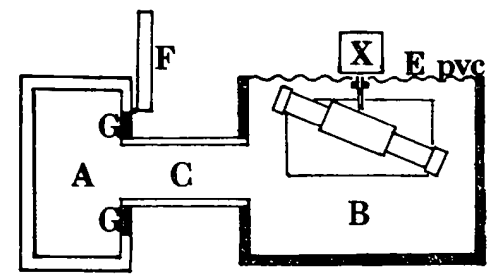

Fig. 1. Schematic diagram of the apparatus. case of the use of the precession camera the sheet of PVC allows the oscillation movement of the apparatus. The freezer's lateral door $F$ is open and replaced by an insulated panel $G$ several $\mathrm{cms}$ thick. The tube $C$ goes through the panel as shown in Fig. 1. Cold air thus passes from freezer $B$ to box $A$.

\section{Characteristics}

This arrangement permits the maintenance in the chamber of a temperature of $10^{\circ} \mathrm{C}$ for several months, when the ambient temperature is between 25 and $30^{\circ} \mathrm{C}$. Probably the temperature could be lowered even further by circulating the air (ventilator in $C$ and an extra tube for air return).

\section{Advantages}

- The installation is very simple and costs very little as the freezer is not modified and could be used at any time for other purposes.

- the diffraction chamber is easily accessible.

- the supervision required is practically none.

- No trosting problems of sample or blocking in tube: all the frost takes place in the freezer which can be defrosted quickly once a week.

\section{Remarks}

- The PVC carbonizes with time over the area where $X$-rays penetrate but this orifice does not appreciably affect the temperature obtained.

- If it were possible to have a freezer of several hundred litres capacity, we could put both the chamber and the $X$-ray tube in this freezer. This would permit the lowering of the temperature to around $0^{\circ} \mathrm{C}$.

MICHEL TACHEZ FrançOIS THÉOBALD
Faculté des Sciences

Laboratoire de Chimie-Physique 32 rue Mégevand 25030 Besançon France

(Received 18 March 1975; accepted 11 April 1975)

\section{Crystallographers}

This section is intended to be a series of short paragraphs dealing with the activities of crys. tallographers, such as their changes of posi tion, promotions, assumption of significant new duties. honours, etc. Items for inclusion, sub ject to the approval of the Editorial Board, should be sent to the Executive Secretary of the International Union of Crystallography (J.N. King. International Union of Crystallography 13 White Friars, Chester CH1 $1 \mathrm{NZ}$, England).

Professor G. Allegra, Istituto di Chimica, Politecnico di Milano, has been appointed a Co-Editor of Acta Crystallographica.

Frofessor Kedareswar Banerjee, the pioneer X-ray crystallographer in India, died on 30 April 1975. Early in his career he determined the structures of napthalene and anthracene. In 1931, he worked with Sir William Bragg and developed one of the first direct methods of crystal structure determination. He was Professor of Physics at the Indian Association for the Cultivation of Science from 1943 to 1952 and Director of the Association from 1959 until his retirement in 1965. Between 1952 and 1959 he was Head of the Department of Physics at Allahabad University. His interests in crystallography were widespread and, with his death, India has lost a renowned teacher. 
Professor G. M. Brown, Professor of Geology at the University of Durham, Professor J. W. Christian, Professor of Physical Metallurgy at the University of Oxford, Dr A. R. Lang, Reader in Physics at the University of Bristol, and Professor R. Mason, Professor of Chemistry at the University of Sussex, have been elected Fellows of the Royal Society.

Dr G. F. Claringbull, Director of the British Museum (Natural History), and Professor P. B. Hirsch, Isaac Wolfson Professor of Physical Metallurgy at the University of Oxford, have been knighted.

Dr Michael Hart has been seconded to the Central Policy Review Staff but he will continue his duties as a CoEditor of Journal of Applied Crystallography from Bristol.

Professor Clifford G. Shull, Professor of Physics at the Massachusetts Institute of Technology, Cambridge, U.S.A., has been elected to the National Academy of Sciences.

Professor A. R. J. P. Ubbelohde, Professor of Thermodynamics at $\mathrm{Im}$ perial College, London, has been awarded the George Skakel Memorial Award by the American Carbon Society.

\section{Notes and News}

Announcements and other items of crystallographic interest will be published under this heading at the discretion of the Editorial Board. The notes (in duplicate) should be sent to the Executive Secretary of the International Union of Crystallography (J. N. King International Union of Crystallography 13 White Friars Chester $\mathrm{CH} 1$ $1 \mathrm{NZ}$, England).

\section{StructureReports}

In addition to the five volumes of Structure Reports published in November 1974 (Volumes 30B, 31B, 32B, 33B and $35 B$, covering the organic literature for 1965-68 and 1970), five more volumes have just been published. These latest volumes cover all the literature for 1963 and the literature for metals and inorganic compounds for 1965, 1966, 1968 and 1970. All the annual volumes, up to and including Volumes $39 A$ and $39 B$ (for 1973), should be published by the end of 1975 . This will bring Structure Reports up to date and make it even more useful to all crystallographers.

The five volumes just pub!ished are:
Volume 28 , covering all the literature for 1963 (viii +723 pages). Price: 225 Netherlands guilders.

Volume $30 A$, covering the literature for metals and inorganic compounds for 1965 (viii +487 pages). Price: 75 Netherlands guilders.

Volume $31 A$, covering the literature for metals and inorganic compounds for 1966 (viii +278 pages). Price: 75 Netherlands guilders.

Volume $33 A$, covering the literature for metals and inorganic compounds for 1968 (viii +535 pages). Price: 95 Netherlands guilders.

Volume $35 \mathrm{~A}$, covering the literature for metals and inorganic compounds for 1970 (viii +499 pages). Price: 95 Netherlands guilders.

Orders may be placed direct with the publisher (Oosthoek, Scheltema \& Holkema, Emmalaan 27, Utrecht, The Netherlands), with Polycrystal Book Service, P.O. Box 11567, Pittsburgh, Pa. 15238, U.S.A., or with any bookseller. Details of price reductions for personal subscriptions and for standing orders may be obtained direct from Oosthoek, Scheltema \& Holkema or from Polycrystal Book Service.

\section{Book Reviews}

Works intended for notice in this column should be sent direct to the Book-Review Editor (M. M. Woolfson, Physics Department, University of York. Heslington York YO1 5DD. England). As far as practicable books will be reviewed in a country different from that of publication.

\section{Technische Mineralogie. Band 7. Materialverhalten aniso- troper Festkörper. By $W$.} DREYER. Pp. $x+395$, Figs. 120 ,

Tables 41. Vienna, New York: Springer-Verlag, 1974. Price (Bound) S894,00, DM125,00, U.S. $\$ 51,30$.

The opening chapter - on the present state and aims of research on crystalline textures - indicates the particular contribution which this book makes to the literature. The next two chapters give a very exhaustive mathematical presentation of the analysis, much of which is used in later chapters. The four remaining chapters treat of thermal expansion, thermal conductivity, electrical conductivity and dielectric susceptibility respectively. In each chapter the tensor treatment is first given for single crystals and then this is followed by the modifications necessary for polycrystalline specimens, such as rocks or rolled metal sheets. The effect of preferred orientation is carefully analysed. There are many examples of the working out of the principal coefficients from the quantities measured on particular kinds of crystals going from triclinic through all the systems down to cubic. There are also many tables of the physical constants relating to these four properties thermal expansion, conduction (thermal and electrical) and dielectricity.

There are a few errors. On p. 87 a $1 / 3$ has been omitted in equations $738 / 740$ and a 3 in equation 741. On p. 88 the calculated values of the principal coefficients of expansion are incorrect both in magnitude and direction. On p. 92 the formula 762 introduces confusion because $\tan ^{2} 20=\tan ^{2}(\pi-20)$. As a result the value of the expansion coefficient calculated from the formula is incorrect.

The book is beautifully printed and the illustrations are numerous and very clear. The bibliography is extensive. The book can be warmly recommended, both for the detailed working out from practical measurements of second-order tensor properties and also for the mathematical treatment of polycrystalline aggregates.

W. A. WOOSTER

Brooklyn Crystallographic Laboratory Bottisham

Cambridge

England

The chemistry of imperfect crystals. BY F. A. KROGER. Vol. 1. Pp. xiii +313 , Figs. 58 , Tables 10. Price $f 70.00$ (about U.S. $\$ 25.50)$. Vol. 2: pp. 1000. Price f275.00 (about U. S. \$105.75). Vol. 3: pp. xiv +306 , Figs. 42, Tables 15. Price $f 100$ (about U.S. \$38.50). Amsterdam: North Holland, 1974.

This is a book primarily for research workers already in, or about to enter, the field of solid-state physics, chemistry or materials science; it is a book for the working specialist, rather than the amateur. It concedes little to a user unfamiliar with crystal structures or who does not already know the context and priorities of the subject.

The first edition was published in 